Marquette University

e-Publications@Marquette

$10-1-1995$

\title{
Advertising Research Issues from FTC Versus Stouffer Foods Corporation
}

\author{
J. Craig Andrews \\ Marquette University, craig.andrews@marquette.edu \\ Thomas J. Maronick \\ Towson University
}

Published version. Journal of Public Policy \& Marketing, Vol. 14, No. 2 (Fall 1995): 301-309.

Permalink. (C) 1995 American Marketing Association. Used with permission. 


\title{
Legal Developments Special Issue on Advertising Law and Regulation
}

\author{
Jef I. Richards \\ Guest Editor \\ University of Texas, Austin
}

\section{Advertising Research Issues From FTC Versus Stouffer Foods Corporation}

\section{J. Craig Andrews and Thomas J. Maronick ${ }^{1}$}

Extrinsic evidence is frequently offered in Federal Trade Commission advertising deception cases, most often in the form of advertising research, such as copy tests. Although generally accepted principles exist for copy test evidence presented before the Commission, how these principles are operationalized can provide fertile ground for challenges. Thus, the authors review six copy testing and ad interpretation issues from the recent Stouffer Foods case. The authors discuss difficult tradeoffs inherent in relative versus absolute claims, multiple claims, control ad groups, control questions, and disclosure information. The careful consideration of such trade-offs in advertising research decisions will help in the preparation of extrinsic evidence before the Commission.

The role of extrinsic evidence in Federal Trade Commission (FTC) advertising deception cases is becoming increasingly important. Although not required per se, such evidence is nonetheless considered and often given substantial weight in cases regarding implied claims (Thompson Medical Co. 1984, CD at 789), ${ }^{2}$ particularly when a "facial analysis" by the Commission is insufficient. Extrinsic evidence is frequently presented in the form of expert testimony, common usage of terms, generally accepted principles in marketing research, and methodologically sound consumer research studies (Kraft, Inc. 1991, CD at 121-22). In recent years, advertising copy tests tend to represent the primary

${ }^{1}$ J. CRaig ANDrews is Associate Professor of Marketing, Marquette University. Thomas J. Maronick is Associate Professor of Marketing, Towson State University. The first author served as a Consumer Research Specialist with the Division of Advertising Practices at the FTC from 1992 to 1993. The second author was formerly the Head of the Office of Impact Evaluation at the FTC, and currently is an in-house FTC consultant for marketing and advertising research. The views expressed are those of the authors and do not necessarily represent the views of the Commission or any of its members. The authors appreciate the helpful comments and suggestions of three anonymous $J P P \& M$ reviewers and the Special Editor on an earlier version of this manuscript.

${ }^{2}$ The following key is used to distinguish among initial decisions by FTC Administrative Law Judges (ALJs), trial briefs, and FTC Commission Decisions:

\footnotetext{
$\mathrm{IDF}=\mathrm{ALJ}$ 's initial decision finding by section number

$\mathrm{ID}=$ ALJ's initial decision discussion by page number

$\mathbf{R B}=$ respondent's (Stouffer's) trial brief page number

$\mathrm{CB}=$ complaint counsel's (FTC's) trial brief page number

$\mathrm{CD}=$ Commission Decision page number
}

form of extrinsic evidence offered. As the Commission notes in Thompson Medical (1984, CD at 789),

The extrinsic evidence we prefer to use and to which we give great weight is direct evidence of what consumers actually thought upon reading the advertisement in question. Such evidence will be in the form of consumer survey research for widely distributed ads....

However, though generally accepted principles and case precedent exist for the use of copy tests in FTC advertising cases, how such principles and precedent are operationalized is likely to vary depending on the context of the case (cf. Maronick 1991). Thus, decisions on copy test methodology represent fertile ground for challenges in FTC advertising deception cases (Jacoby and Szybillo 1995; Maronick 1991; Preston 1987, 1992; Stewart 1995; Sudman 1995). In fact, in the Stouffer Foods Corporation case, $40 \%$ of the recent Commission opinion (Stouffer Foods Corp. 1994, CD at 9-17) and almost 66\% of the Administrative Law Judge's (ALJ) initial decision (Stouffer Foods 1993, ID at 29-36, 38) involved consideration of the probative value of methodologies employed in the complaint counsel (i.e., FTC) and respondent (i.e., Stouffer Foods) copy tests.

Thus, given the potential for challenges, the purpose of our review is to discuss six important copy test and ad interpretation issues raised in the recent Stouffer Foods case. These six issues are (1) conveyance of relative and absolute claims, (2) multiple ad claim interpretation, (3) the use of control ad groups and open-ended questions, (4) pre-existing beliefs and the role of control ad groups, (5) the role of control questions and their interpretation, and (6) the processing of disclosure information. The purpose of our discussion is to help provide guidance for those preparing cases with extrinsic evidence for FTC consideration. In examining the often difficult trade-offs in the design of such copy tests, we incorporate a variety of principles from consumer, advertising, and marketing research. Before examining these points, however, we present a brief review of the Stouffer Foods case and the specific complaint.

\section{Case Background and Complaint}

In 1991, the FTC issued a complaint against Stouffer Foods, alleging that Stouffer violated Sections 5 and 12 of the FTC Act by disseminating ads that falsely represented the sodium content of its Lean Cuisine entrees (Stouffer Foods 1994, $\mathrm{CD}$ at 1). Specifically, the complaint alleged, first, that Stouffer's ads falsely represented Lean Cuisine entrees as low in sodium through statements such as: they "skimp on: Calories. Fat. Sodium. With less than 300 calories, controlled fat and always less than 1 gram of sodium per entree, we make good sense taste great." The complaint also noted 
that a footnote in fine print from the ads stated: "All Lean Cuisine entrees have been formulated to contain less than 1 gram (1000 milligrams) of sodium." Second, the complaint alleged that the ads failed to disclose adequately the material fact that " 1 gram is equivalent to 1000 milligrams, which is the commonly used unit of measurement for sodium" (Stouffer Foods 1993b, ID at introduction). ${ }^{3}$

In reply, Stouffer argued (among other issues) that its campaign focused on great taste, controlled fat, calories, and sodium. Furthermore, Stouffer contended that the sodium content claim was relative in nature, expressing a reduction (i.e., lower) in the sodium amount, but not implying low sodium, which consumers associated with bland taste (Stouffer Foods 1993b, ID at 27).

Based on the trial evidence, the ALJ concluded that Stouffer did misrepresent their Lean Cuisine entrees as low in sodium (Stouffer Foods 1993b, ID at 29, 35-36, 39). The Commission agreed with the ALJ on the basis of a facial analysis of the ads and the extrinsic evidence offered by the complaint counsel (see Stouffer Foods 1994, CD at 7, 9, 17).

The ALJ also determined the low sodium claim to be presumptively material, because it significantly involved a health claim important to the audience (Stouffer Foods 1993b, ID at 37). Other evidence for materiality was noted in the ALJ's findings, including the linkage between sodium and high blood pressure, Stouffer's copy test results showing that $68 \%$ of the participants considered sodium to be important in making purchase decisions about frozen entrees, and company research documents and intent (see Stouffer Foods 1993b, IDF 171-81). ${ }^{4}$ The Commission agreed with the ALJ and noted that Stouffer did not challenge the ALJ's findings regarding the materiality of the low sodium claim (Stouffer Foods 1994, CD at 7, n. 11).

Although the ALJ determined that the low sodium claim was material, he also concluded that failing to adequately disclose that one gram was equal to 1000 milligrams was immaterial (Stouffer Foods 1993, ID at 35-38). His reasoning was that, though the sodium content in milligrams was presumptively material, the trial evidence showed that most consumers were unaware of the recommended daily allowance for sodium, and that knowing the precise milligrams of sodium in an entree would be of little use to them (Stouffer Foods 1993b, ID at 38). The Commission agreed that the ads did not adequately disclose that one gram equals 1000 milligrams and noted that the complaint counsel did not appeal the dismissal of the milligram disclosure allegation (see Stouffer Foods 1994, CD at 2).

\footnotetext{
${ }^{3}$ The Commission finds deception if there is a representation, omission, or practice that is likely to mislead consumers acting reasonably under the circumstances, and this representation, omission, or practice is material (Cliffdale Associates, Inc. 1984, CD at 165).

${ }^{4}$ Information is material if it is important to consumers and, therefore, likely to affect their choice of or conduct regarding a product (Cliffdale As sociates, Inc. 1984, CD at 165). Discussion regarding presumptively material claims can be found in Cliffdale Associates (CD at 182-83). See also a discussion of extrinsic evidence offered for materiality in Jacoby and Szybillo (1995), Kraft (1991, CD at 134-38), and Stewart (1995).
}

\section{General Standards for FTC Advertising Copy Tests}

The standard the Commission uses in evaluating advertising claims is the "overall, net impression made by the ad" (Kraft, Inc. 1991, CD at 122; Thompson Medical 1984, CD at 790). The key term in the Commission's consideration of extrinsic evidence, such as advertising copy tests, is generally accepted principles. ${ }^{5}$ Such general standards or principles in Commission cases evolve from the discussion of legal precedent by marketing and legal scholars (e.g., Jacoby and Szybillo 1995; Maronick 1991; Morgan 1990; Owen and Plyler 1991; Plevan and Siroky 1991; Preston 1987, 1989, 1992; Stewart 1995), as well as from the actual FTC cases themselves (e.g., American Home Products Corp. 1981; Bristol-Myers 1975; Kraft, Inc. 1991; Stouffer Foods 1994; Thompson Medical 1984). In general, the Manual for Complex Litigation (1982, p. 120; see also Jacoby and Szybillo 1995), suggests a list of principles to be considered in determining whether a survey offered as evidence was properly conducted, including that:

(1) the proper universe was examined, (2) a representative sample was drawn from that universe, (3) the mode of questioning the interviewees was correct, ... (4) the persons conducting the survey were recognized experts, (5) the data gathered were accurately reported, and (6) the sampling design, the questionnaire, and the interviewing were in accordance with generallyaccepted standards of objective procedure and statistics in the field of such surveys.

As the Manual indicates, once the survey has passed the test of admissibility in trial testimony, objections to the manner in which it was conducted apply to the relative weight of the survey as evidence. ${ }^{6}$ We now explore these principles (and related ones) in terms of their application to evidence offered at the FTC, including that found in Stouffer Foods (1993a, b, c, 1994).

\section{Universe and Sample}

The Commission has determined that surveys are to be based on valid samples drawn from the appropriate population, ask appropriate questions that minimize bias, and analyze results correctly (Thompson Medical 1984, CD at 790). Specifically, the Commission has determined that the sample should be representative of the appropriate universe (e.g., potential purchasers of the advertised product, given the appropriate target market characteristics; cf. Thompson Medical 1984, CD at 795). In Stouffer Foods (1993b, IDF

\footnotetext{
${ }^{5}$ These principles are not necessarily consistent with all principles for copy tests (or their application) found in the ad industry or in Lanham Act cases, whereby one company sues another in federal court for misleading advertising claims. In the case of the ad industry, copy test objectives can include persuasive aspects of the ad beyond the FTC objectives of measuring the conveyance of a particular ad claim (cf. "Positioning Advertising Copy Testing" 1982). In Lanham Act cases, the burden of proof is on the plaintiff, because they must affirmatively prove the claim in question is false and misleading, not merely that it is unsubstantiated (American Home Products v. The Procter \& Gamble Co., Syntex USA, and Procter-Syntex Health Products 1994 at 13, n. 14; Preston 1987, pp. 687-89).

${ }^{6}$ Interested readers are directed to a discussion of these and related principles for designing and conducting survey and copy test evidence for use at trial in Jacoby and Szybillo (1995), Maronick (1991), Morgan (1990), Plevan and Siroky (1991), and Stewart (1995).
} 
69), the complaint counsel's (i.e., the Commission's) copy test sample was drawn from a "universe consisting of women who were principal food shoppers for their household, between the ages of 25 and 54, who had purchased a frozen entree in the last three months and who were not following a medically supervised diet." Stouffer argued (Stouffer Foods 1993c, RB at 40-44) that the universe from which the complaint counsel's sample was drawn was too narrow and excluded portions of the Lean Cuisine purchasing and consuming population at whom the challenged ads were directed (e.g., women younger than 25 years of age and older than 54 years of age, men of all ages, and those on medically supervised diets). However, though recognizing this potential defect, the ALJ concluded that "...there is no evidence to show that the results would have differed if [the excluded categories] would have been included, and there is no doubt that those surveyed were the bull's eye of the target at which the ads were aimed" (Stouffer Foods 1993b, ID at 30).

Stouffer's copy test relied on a universe of "potential purchasers of Lean Cuisine, regardless of whether they were in the target audience for the ads" (Stouffer Foods 1993b, IDF 121). The ALJ concluded (Stouffer Foods 1993b, ID at 35) that Stouffer's universe was defective because of (1) the skewing of the sample toward men and older participants and (2) the exclusion of Stouffer's "Red Box" entree purchasers (Stouffer Foods 1993b, IDF 122-25).

It should also be noted that the FTC does not require that a probability sample be drawn. In Bristol-Myers (1975, CD at 744, n. 14), the FTC reasoned that "... while the samples were not scientifically drawn utilizing probability sampling procedures, those interviewed probably reasonably represented the class of antiperspirant or female antiperspirant users." Furthermore, the FTC views the use of mall intercepts for data collection favorably in sampling design (Thompson Medical 1984, CD at 794-95), in part because such studies are the generally accepted methods for advertising copy-test research.

\section{Design Issues}

One study design issue, receiving perhaps the most recent attention by the FTC, is that of the appropriate controls to use to enhance the validity of the results (Kraft, Inc. 1989, IDF 121). The use of a control ad group (e.g., respondents who see a control rather than a test ad) may help to ensure that responses to the challenged ad claims are not due to factors other than the challenged ad claims in question. In addition, certain copy test questions may prompt biasing, such as a yea-saying response. In this case, using one or more control questions about a claim not appearing in the challenged ad, yet one that is plausibly associated with the product, is important for measuring the extent of yea-saying bias in response to closed-ended questions. Arguments regarding the nature and type of controls were prevalent in Stouffer Foods (1993b, IDF 11, 13-15, 18-20, ID at 31-35, 1994, $\mathrm{CD}$ at $10-17)$ and are subsequently discussed in this article.

\section{Questionnaire Issues}

In examining challenged ads and claims, the FTC considers the "...overall net impression made by the ad to determine what messages it reasonably can be interpreted as conveying to consumers" (Thompson Medical 1984, CD at 790; see also Cliffdale Associates, Inc. 1984, CD at 175, n. 4). In terms of format, survey questions generally follow a funnel approach; that is they begin with general open-ended questions and ask successively narrower questions, ending with specific closed-ended questions (Kraft, Inc. 1989, IDF 110). For open-ended questions, sufficient probing is necessary to elicit consumer understanding of the implied claims. In the case of closed-ended questions, potential order biases of not only the questions, but also of response options, can be examined through rotating study questions and providing multiple response options (cf. Stouffer Foods 1993b, IDF 129-33). Additionally, the FTC views the provision of "don't know" options and instructions in the questionnaire favorably when it examines copy test results (Stouffer Foods 1993b, IDF 96-97, 1994, CD at 11, 12; see also Plevan and Siroky 1991, p. 633). Finally, the questionnaire and procedures should be pretested to detect potential problems (e.g., leading questions, questions that are not mutually exclusive) before the administration of the final study.

In the Stouffer case, the ALJ found the complaint counsel (FTC) copy test to be probative because it started with "unbiased open-ended questions" (Stouffer Foods 1993b, IDF 81, ID at 31) and because "the closed-ended questions were rotated" (Stouffer Foods 1993b, IDF 98-99, ID at 33). On the other hand, the ALJ found the Stouffer Foods copy test less probative because of its "methodological deficiencies," including the fact that the respondents were not funneled from open-ended questions to closed-ended questions (Stouffer Foods 1993b, IDF 120, 126-27). Citing trial testimony, the ALJ noted: "It is not appropriate to start a copy test with (closed-ended) questions" (Stouffer Foods 1993b, IDF 128).

\section{Experience Counts}

Perhaps one of the more important of the generally accepted principles at the Commission is that experience and competence count in all aspects of the copy test (Maronick 1991). For example, in Bristol-Myers (1975, CD at 744, n.14), the importance of experience is cited for the research organization; the type of research conducted by the organization; and those involved in the research design, supervision, and interviewing activities of the study. Such experience in the design and execution of the complaint counsel's copy test in the Stouffer Foods case was noted by the ALJ (Stouffer Foods 1993b, IDF 52, 61, 67).

\section{Data Reporting}

An important issue in previous Commission decisions has been the appropriate reporting of the verbatims, that is, the outcome of open-ended questions (Preston 1987, pp. 656, 683). For example, the Commission rejected evidence for verbatim responses not placed on the record (Thompson Medical 1984, CD at 795) and not properly coded (Standard Oil of California 1974, CD at 1401; Thompson Medical 1984, CD at 795). It is noteworthy that the record in Stouffer Foods (1993a, b, c) does not indicate any problems with the coding of the open-ended results. This, no doubt, reflects that both parties used experts experienced in conducting consumer survey research. 


\section{Ad Stimuli Concerns}

In addition, difficult aspects of the ad stimuli can present challenges to those designing copy tests for litigation and in the interpretation of challenged claims. For example, the interpretation of relative (e.g., lower) versus absolute (e.g., low) claims, the interaction or relationships among multiple claims, and consumer interpretation of disclosure information may be at issue, as is argued in Stouffer Foods (1993c, RB at 19-35; 1994, CD at 7,8). We now examine our six ad interpretation and copy test issues as they. relate to the Commission decision and rationale presented in the Stouffer Foods case.

\section{Relative and Absolute Claims}

In his decision, the ALJ found that the Lean Cuisine ads conveyed a "low sodium claim to reasonable consumers" (Stouffer Foods 1993b, ID at 29). On appeal, Stouffer argued the ALJ had ignored elements in the ads that conveyed that Lean Cuisine products had a reduced or lower quantity of sodium, rather than an absolute low amount (Stouffer Foods 1994, CD at 7). One challenged radio ad, cited by the ALJ, describes Lean Cuisine entrees as follows: "These babies are healthier than ever. Lower in sodium, fat and cholesterol. Read those boxes, people, these numbers are low" (Stouffer Foods 1993b, ID at 29). Stouffer argued (Stouffer Foods 1993c, RB at 38-39, see also RB at 24) that the relative information in the ad (e.g., "healthier," "lower") was prominent and would contradict impressions of "absolute lowness" taken from other aspects of the ad (e.g., "these numbers are low"). As their legal basis for this argument, Stouffer cited Thompson Medical (1984, CD at 793, 803), in which the Commission notes that contradictory elements in the ads precluded determining with sufficient certainty what message viewers gained from the ads.

The Commission, however, saw no basis for concluding that the reduced and low sodium claims are mutually exclusive (Stouffer Foods 1994, CD at 8). As reasoned by the ALJ and accepted by the Commission (Stouffer Foods 1994, CD at 8), the comparative, "lower in sodium," does not conflict with the absolute claim, "these numbers are low." Relying on Kraft's added copy modifications and disclosures (Kraft, Inc. 1991, CD at 10), the ALJ cited the need for a conflicting statement in an ad to be effective. Thus, the ALJ viewed the comparative statement ("lower in sodium") as not derogating the net impression (the FTC standard) that the Lean Cuisine entrees are low in sodium. The Commission Decision (Stouffer Foods 1994, CD at 6, 8) adopted the ALJ's view and added that reducing the amount of undesirable elements often results in a perception of diminishing that element to a low (i.e., absolute) level.

The Commission Decision is consistent with research on incomplete comparatives in advertising (e.g., "Brand $\mathrm{X}$ is lower"-without explicitly saying "lower than what"), which has shown that consumers often draw overall inferences far beyond the incomplete content of the comparative statement (Shimp 1978). Thus, an absolute (e.g., "Brand X is low") response might be generated from the incomplete comparison that "Brand X is lower." Additionally, the Commission Decision is consistent with consumer research, which has shown that the reliance on simplifications (versus complete information) is greater for novices (i.e., ordinary consumers) than experts (Alba and Hutchinson 1987).

Perhaps the greatest weight on the relative-absolute issue was given to the copy test results by the complaint counsel (FTC). This was because the FTC's copy test made it possible to distinguish between relative and absolute responses to open-ended questions and found that only 5 to $14 \%$ of respondents provided a "less/lower/reduced" sodium response, whereas 43 to $60 \%$ provided a "low" sodium response (Stouffer Foods 1994, CD at n. 14).

\section{Interpretation of Multiple Ad Claims}

The second issue concerns the interpretation of multiple claims in ads. Often, the interaction of multiple claims in a challenged ad presents interpretational problems for researchers and potential grounds for appeals. These problems result when other ad executional elements and copy points are argued in FTC cases to have attenuated the effects of the challenged claim in question (cf. "ineffective qualification implication," Preston 1989, pp. 1281-84). For example, Stouffer argued, based on Thompson Medical (1984, CD at 793), that the great taste component of the challenged ads served to contradict or neutralize the low sodium message (Stouffer Foods 1994, CD at 7). However, the Commission disagreed, citing a lack of evidence that a superior taste message necessarily contradicts a low sodium claim or that the existence of a nondeceptive message precludes the finding of an implied deceptive claim. The Commission argued that an ad can convey more than one claim and that not all claims need to be deceptive for the net impression of the ad to be viewed as deceptive (Cliffdale Associates, Inc. 1984, CD at 178).

In contrast, problems can arise when multiple claims in an ad are related (versus conflicting) and when one of the claims directly or indirectly reinforces a challenged claim. These multiple, related claims facilitate what is known as relational processing, which involves focusing on similarities or shared themes among disparate pieces of information (Meyers-Levy 1991; see also Stouffer Foods 1993a, CB at 16). This contrasts with item-specific processing, which focuses on aspects that are unique or distinctive to a particular claim. For example, in the Stouffer case, related claims in the "Make Sense" ad are cited by the Commission as representing low levels of undesirable nutrients. As noted by the Commission (Stouffer Foods 1994, CD at 6):

"Calories. Fat. Sodium." are "skimp[ed] on." The additional language in the Make Sense ad "With less than 300 calories, controlled fat and always less than 1 gram of sodium* per entree..." also reinforces the low sodium message.

A second consumer processing issue regarding multiple, related claims in an ad considered in the Stouffer case is that of priming (cf. Herr 1989). Priming involves providing consumers with exemplars or cues that serve to bias their thinking in a certain direction. For example, testimony from Stouffer Foods (1993a, CB at 16) indicated that the three Lean Cuisine ads ("Make Sense," "300 Like a Million," and "Lean on Lean Cuisine") all used language in their headlines to prime consumers to read and process the ads from a "healthy eating" frame of reference. The Commission (Stouffer Foods 1994, CD at 8) termed this as 
"condition[ing] the reader to think that Lean Cuisine is a healthy product," on the basis of ad copy regarding healthy ingredients and small quantities of undesirable ingredients. The Commission (Stouffer Foods 1994, CD at 6) noted that "These (positive) representations communicate that the negative attributes have been reduced to meager quantities."

Unfortunately, though the presence of multiple, related claims provides interesting facial analyses of challenged claims, it can also present difficult problems in the construction of control ads for copy tests.

\section{Control Ad Issues}

Our third and fourth research points from the Stouffer case are concerned with issues associated with (1) the use of a control ad group for open-ended questions and (2) the use of a control ad group to measure pre-existing beliefs. Both these points were important appeal arguments made by Stouffer Foods in challenging the methodology of the copy test conducted for the complaint counsel (Stouffer Foods 1994, CD at 12).

\section{The Nature of Controls}

In any study, it is important to have the ability to control the situation in which the study is being conducted so as to eliminate the role of extraneous forces and competing explanations (Cook and Campbell 1979, pp. 7-9). A control ad is often used to separate effects due to the challenged ad claim from effects due to external factors associated with such an ad claim. Such external factors include previous exposure to the ad, other nonchallenged executional and copy point elements in the ad, and prior beliefs and knowledge associated with the advertised product (Cohen 1977; Kraft, Inc. 1989, IDF 121, 126; Mitchell 1983; Russo, Metcalf, and Stephens 1981, n. 10; Stouffer Foods 1994, CD at 12). The control ad group, to which respondents are randomly assigned, receives a control ad with as few differences from the challenged test ad as possible--with the exception of the challenged claim (Kraft, Inc. 1989, IDF 147). Thus, the control ad group attempts to account for a priori differences that respondents bring with them to the study setting. ${ }^{7}$ The difference between positive responses to the test and control ads represents the "minimum number of individuals who would take that particular claim away from the ad" (Kraft, Inc. 1989, IDF 125). As indicated by the testimony in Kraft (1989, IDF 124), the basis for the conservative nature of the procedure is that:

...it is reasonable to conclude that some of the positive control group responses were based on prior exposure to the challenged ads and thus are attributable to those ads. Because this is not an absolute certainty, all positive control group responses are subtracted from the positive test ad responses.

In contrast, the control question is a post hoc control for external measurement error that may result from the provision of a closed-ended question format. Such measurement

\footnotetext{
${ }^{7}$ It should be noted that with most control ad group types, respondents actually view a control ad (e.g., a purged or tombstone ad, a different ad for the same brand, or a corrected ad). However, in one control group type (i.e., the nonexposure control), respondents do not see any ad. We explore characteristics and trade-offs of these control ad group choices subsequently.
}

concerns include yea-saying bias, inattention, halo effects, or other noise factors (Stouffer Foods 1993b, IDF 104).

\section{Control Ad Groups and Open-Ended Questions}

In preparation for trial and on appeal, Stouffer argued that the complaint counsel's methodology was fatally flawed because of the absence of a control ad group (Stouffer Foods 1993c, RB at 44, 1994, CD at 12). Specifically, Stouffer argued, citing Thompson Medical (1984) and Kraft (1989, 1991), that "the FTC has made abundantly clear that a control ad is required to be used for both open-ended and closed-ended questions" before survey results can be relied on (Stouffer Foods 1993c, RB at 44). Stouffer argued that the Commission accepted as reliable a survey in Kraft in which a control ad was used for both open-ended and closed-ended questions (Kraft, Inc. 1989, IDF 120-23) and rejected as unreliable a copy test in which control measures were not used to correct for pre-existing or inherent survey bias (Kraft, Inc. 1991, CD at n. 19). Stouffer also noted (Stouffer Foods 1993c, RB at 46, 66-67, 1994, CD at 12) that in Thompson Medical (1984, CD at 806-808), the Commission accepted as reliable the ASI theater test for the challenged Aspercreme ad that included a control ad for a competing product, Mobisyl. The Aspercreme ad was challenged on the basis that it conveyed the false impression that Aspercreme contained aspirin. Responses to the open-ended (unaided recall) question indicate that consumers thought aspirin was an ingredient in Aspercreme (17\%), but not in Mobisyl (1\%).

In discussing Stouffer's arguments related to Thompson Medical, however, the ALJ noted that the Commission in that case did not directly subtract the control responses in the analysis of the Aspercreme ad (Stouffer Foods 1993b, ID at n. 11; see also 1994, CD at n. 30). In addition, the Commission noted (Stouffer Foods 1994, CD at 14) that Stouffer's reliance on Thompson Medical and Kraft as mandating a control ad was misplaced. In its decision in Stouffer Foods (1994, CD at 14,15), the Commission indicated that there is nothing in Commission precedent requiring the use of a control ad for open-ended questions, nor dictating the type of control necessary in the case of closed-ended questions. However, it is noteworthy that this standard, namely, that a control ad is not necessary, is likely to be inconsistent with certain Lanham Act cases involving exploitive misleadingness, in which the court has said that "a control mechanism would likely be "indispensable"" (see Johnson \& Johnson * Merck Pharmaceuticals Co. v. Smithkline Beecham Corp. 1992, at 301; American Home Products v. The Procter \& Gamble Co., Syntex USA, Inc., and Proctor-Syntex Health Products Co. 1994, at 10). ${ }^{8}$

\footnotetext{
${ }^{8}$ Exploitive misleadingness occurs when an advertiser does not mislead by creating false beliefs or impressions, but by exploiting those that already exist (Russo, Metcalf, and Stephens 1981, p. 125). In Johnson \& Johnson * Merck Pharmaceuticals Company v. Smithkline Beecham Corporation (at 301), Johnson \& Johnson contend that Smithkline Beecham's ad for Tums capitalized on "the unsubstantiated belief that aluminum causes Alzheimer's disease." However, Johnson \& Johnson's extrinsic evidence to support this contention was not given weight by the court partially because of the lack of a control ad group to account for these preconceived beliefs.
} 


\section{Control Ad Groups and Pre-Existing Beliefs}

Stouffer argued that some number of survey respondents were likely to come to the test with a pre-existing belief that Lean Cuisine frozen entrees were low in sodium (Stouffer Foods 1993 c, RB at $44-49,1994, \mathrm{CD}$ at 12-13). Therefore, Stouffer argued that the complaint counsel's copy test should have employed a control ad group to "quantify and eliminate the effects of participants' pre-existing bias" (Stouffer Foods 1994, CD at 12-13). However, though the Commission acknowledged that the failure to control for pre-existing beliefs introduces a potential for bias (Stouffer Foods 1994, CD at 13, 16-17), it also indicated that Stouffer failed to establish that pre-existing beliefs affected the complaint counsel copy test results (Stouffer Foods 1994, $\mathrm{CD}$ at n. 29). In fact, as the ALJ noted, testimony revealed consumers believed Lean Cuisine's sodium content was actually high (Stouffer Foods 1993b, IDF 87-89). As a result, and contrary to the view of Stouffer, there was less of a need for a control ad in the copy test methodology in accounting for pre-existing beliefs of respondents. ${ }^{9}$

With regard to the Commission's decision concerning the use of control ads to measure pre-existing beliefs, the implication for consumer researchers is that it is desirable to first understand and account for the extent and direction of any strongly held pre-existing bias, because "respondents may be held liable for the dissemination of ads that capitalize on pre-existing consumer beliefs" (Stouffer Foods 1994, CD at n. 31, citing Simeon Management Corp. v. FTC 1978, p. 1137, 1146). Also, conditions may exist in which other ad control types and methods are acceptable (cf. Kraft, Inc. 1989, IDF 126, 147-150); the use of a control ad may be impractical (Kraft, Inc. 1989, IDF 149); or its use may lead to the "overcontrolling" of the study, because the pre-existing beliefs may already be favorable to the party's view or may not affect the copy test results in any way. In summary, though there are certain situations in which a control ad may not be feasible, researchers should be prepared for challenges if one is not included in the study.

\section{Control Ad Group Choices and Problems}

There are three generally recognized control ad groups: Respondents can be shown (1) a purged, cleansed, or tombstone ad that is identical to the challenged ad, except that the potentially misleading claim is removed, (2) a different ad

\footnotetext{
${ }^{9}$ It should be noted, however, that the direction of pre-existing belief biases may sometimes match those conveyed by the advertisement in copy tests. In American Home Products v. The Procter \& Gamble Company, Syntex USA, and Procter-Syntex Health Products (1994), the plaintiff (American Home Products) was seeking a preliminary injunction against the defendant's advertising, alleging that the Procter \& Gamble Aleve ads conveyed false and misleading claims that American Home Products' Advil was less effective and provided less pain relief than Aleve. The plaintiff's survey, indicating that 30 to $35 \%$ of respondents received a message of Aleve's superior duration and efficacy over Advil, was criticized by the court for not "properly control[ling] for preconceptions (both accurate and inaccurate) that consumers may possess given their continual exposure to OTC products and advertising" (at 9-10). The court gave substantial weight to a survey conducted for the defendant in which, in response to one question, "How long do you think Advil lasts?" $50 \%$ of the respondents indicated the analgesic effects of Advil lasted only two to six hours, with only $7 \%$ responding that Advil lasted longer than seven hours. Based, in part, on this evidence, the court ruled against granting the preliminary injunction on behalf of American Home Products.
}

for the same brand, yet one that does not contain the challenged claim, or (3) no ad at all (i.e., a nonexposure control) (Kraft, Inc. 1989, IDF 147-50; Plevan and Siroky 1991; Stouffer Foods 1993b, IDF 134).

In practice, difficult trade-offs and decisions must be made in the selection of the appropriate control ad type. For example, the first approach, using the purged or cleansed ad control, may be the best choice when the control ad is virtually identical to the challenged or test ad, with the exception that the challenged claim is excised. ${ }^{10}$ In practice, however, a situation might arise in which almost everything in the ad is part of the challenged claim. This may even include a product's brand name (e.g., "Aspercreme" or "Lean Cuisine") or prominent executional features. Thus, a purged or cleansed ad would be difficult to use because it would require the deletion of almost all of the ad elements (Stouffer Foods 1993b, IDF 139, 147). Such a deletion acquires a "tombstone" format, and the inherent risk is that executional differences between the tombstone and test ads are pronounced. This can be mitigated somewhat by using other similar clutter or distractor ads in the copy test procedure. Another danger in using a tombstone or purged ad control occurs when the challenged ad has received extensive and recent prior dissemination (Kraft, Inc. 1989, IDF 150). In this case, respondents may rely on their recent memory of the prior ad or may respond to recognizable cues present in the tombstone or purged ad.

The second approach to control ads uses a different ad for the same brand (e.g., "Taste of Cheese" in Kraft, Inc. 1989, IDF 120, 147-50). Because strong halo effects may be associated with brands for long-running ad campaigns (see Mazis, McNeil, and Bernhardt 1983), a different ad (without the challenged claim) for the same brand is sometimes recommended (Kraft, Inc. 1989, IDF 126, 149-50). Yet, this choice is open to criticism if strong brand halo effects are present (Kraft, Inc. 1989, IDF 148). For example, the challenged Kraft Singles campaign was cited as reaching $95 \%$ of the U.S. population an average of nine times in 1985 (Kraft, Inc. 1989, IDF 149). However, as indicated by the ALJ, using a different ad control in this situation generated responses ranging from only 0 to $30 \%$ compared to test ad responses ranging from 47 to $74 \%$ (Kraft, Inc. 1989, IDF 131). Finally, Maronick (1991) notes that the researcher's challenge is to find an ad that holds executional and other features of the test and control ad constant. Ideal candidates also come from different campaigns than that of the challenged ad.

The third approach, the use of the nonexposure control group, asks respondents, who are not shown any ad, questions such as: "Based on everything that you have seen or heard, does Product X contain Y?" The problem with this approach, however, is that the comparison of nonexposure and test control group responses is impractical in cases in which "a limited number of consumers in the universe [are] not ... previously exposed to the challenged ads" (Kraft, Inc.

\footnotetext{
${ }^{10}$ See also Cohen's (1977) testimony describing the advantages and dis advantages of a tombstone (i.e., "bare bones") advertisement as a control or baseline measure.
} 
1989, IDF 149). ${ }^{11}$ Thus, in such a situation, the nonexposure and test group responses are likely to be, a priori, close in nature. Also, the nonexposure control group may introduce potential measurement bias, because the context of the questions associated with this control are not directly related to a specific ad.

In the Stouffer Foods case, the complaint counsel (FTC) did not use a control ad group. Stouffer, on the other hand, used a cleansed ad as a control. However, the ALJ (Stouffer Foods 1993b, IDF 138-40) questioned its effectiveness, because even as cleansed, "the ads contain elements likely to convey a low sodium message and ... were related to sensible, health eating." Thus, the ALJ viewed this cleansed ad as "a control that assured the outcome" (Stouffer Foods 1993b, ID at 35 ).

\section{Control Question Issues}

The fifth issue raised in the Stouffer Foods case relates to the inclusion of a control question about a plausible attribute related to the product, yet not related to information in the challenged ad or claim. This practice is important for measuring the extent of yea-saying, inattention, and other noise factors from closed-ended questions (Stouffer Foods 1993b, IDF 104; Gillette Co. v. Wilkinson Sword, Inc. 1991). The percentage of "yes" responses to the control question is then subtracted from the percentage of affirmative responses to the challenged claim in a closed-ended question (Stouffer Foods 1993b, IDF 106). It should be noted, however, that the Commission does not always subtract control question responses from responses to challenged claims (Thompson Medical 1984, CD at 806-808).

The notion of a control question is analogous to tests for discriminant validity between measures of the target trait or attribute and measures of different traits or attributes (Campbell and Fiske 1959). To be given weight by the Commission, the control attribute selected should be associated with the product, yet not inferred from the challenged ad (Stouffer Foods 1993b, IDF 105, 107). For example, in Stouffer Foods (1994, CD at 12), the Commission found a control question that substituted sugar for sodium to be acceptable. On the other hand, the use of an attribute closely related or frequently confused with one found in the challenged ad (e.g., fat and cholesterol) is not viewed favorably by the Commission (Stouffer Foods 1993b, IDF 111, 1994, $\mathrm{CD}$ at n. 24). In this instance, the ALJ (Stouffer Foods 1993b, IDF 149-52) cited trial testimony showing a high association ( $86 \%$ ) between consuming less fat and controlling higher cholesterol.

\footnotetext{
"Another possibility is to make use of a corrected ad control in which the misleading statement is often corrected in the form of revised ad copy or disclaimers (Russo, Metcalf, and Stephens 1981, p. 123-26). This procedure is argued to work best in cases in which advertisers exploit pre-existing beliefs; however, there is no assurance that such correction will be effective (Russo, Metcalf, and Stephens 1981, pp. 125-26). Such a procedure may also necessitate a two-step process in FTC cases: first, discovering the misleading conveyance based on pre-existing beliefs; second, correcting for it, rather than combining both steps into one.
}

\section{Processing of Disclosure Information}

The sixth issue involves the role of disclosure statements in advertising and their role in Stouffer Foods (1994). Normally, the Commission favors the qualification of ambiguous and misleading claims through the affirmative disclosure of added information (cf. FTC Enforcement Policy Statement on Food Advertising 1994; FTC Guides for the Use of Environmental Marketing Claims 1992; Wilkie 1985). The Stouffer Foods complaint charged as unfair and deceptive, and as a separate violation, the failure to disclose adequately the fact that one gram equals 1000 milligrams (Stouffer Foods 1993b, ID at 37). Testimony revealed that the sodium content of food is commonly measured in milligrams (Stouffer Foods 1993b, IDF 196). In the Stouffer print ads, the Lean Cuisine entrees are described as containing "less than one gram of sodium," with footnotes in small print explaining that one gram is equivalent to 1000 milligrams of sodium (Stouffer Foods 1993b, ID at 37).

Although the Commission favors affirmative disclosures, it generally finds that small print disclosures do not cure misrepresentations created by advertising text (Giant Food, Inc. 1962). In Kraft (1991, CD at 124), later-added copy modifications and fine print disclosures were ineffective in dispelling misleading net impressions (see also Preston 1989, pp. 1281-84). Also, while examining more complex footnote information, Foxman, Muehling, and Moore (1988) found that footnote designations tend to enhance the comprehension surrounding the text material, rather than the information contained in the footnote.

In the Stouffer Foods case, though the ALJ concluded that the adequate disclosure of sodium content is presumptively material, the facts of the case (Stouffer Foods 1993b, IDF 160-62) reveal that most consumers were unaware of the recommended daily allowance of sodium, and knowing the precise milligrams of sodium in an entree would be of little use (Stouffer Foods 1993b, ID at 38). This lack of use was noted by the ALJ, even though trial evidence supported the common misconception by consumers that one gram of sodium is less than 1000 milligrams of sodium (Stouffer Foods 1993b, IDF 163). In her Concurring Statement with the Commission Decision (Stouffer Foods 1994, at n. 1), Commissioner Azcuenaga disagreed on this point. She argued that the disclosure of sodium levels above 600 milligrams would be considered by some consumers to be important to their purchase decisions.

In summary, the findings reveal the difficulty of disclosures to rectify misleading impressions in cases before the Commission. Furthermore, the provision of such disclosure information may be viewed as immaterial by the Commission, as was the case in Stouffer Foods (1993a, b, c, 1994), if, in the Commission's judgment, consumers lack the ability to verify the claims (cf. credence claims in Darby and Karni 1973). However, as was indicated by the ALJ, other more knowledgeable segments, such as those on medically supervised diets, may need such information (Stouffer Foods 1993b, ID at 38). Hence, it is an area for potential methodological conflict over target markets and appropriate samples. 


\section{Implications for Researchers}

Several implications for consumer researchers can be summarized on the basis of our review of important ad interpretation and copy test issues that arise from the Stouffer Foods case, as well as from other FTC case precedent. First, the overriding guide in the Commission's consideration of extrinsic evidence is the researcher's adherence to generally accepted procedures and principles outlined in previous cases before the Commission (e.g., Kraft, Inc. 1991; Stouffer Foods 1994; Thompson Medical 1984) and discussed elsewhere (e.g., Jacoby and Szybillo 1995; Maronick 1991; Preston 1987, 1992; Stewart 1995). One such principle used by the Commission in the evaluation of advertising claims is to consider the overall, net impression made by the ad (Thompson Medical 1984, CD at 790). This Commission standard has been used to evaluate potentially conflicting or supporting relative and absolute information in ads, as well as related multiple claims, some of which are challenged (Stouffer Foods 1994, CD at 7-8). This net impression standard also governs the effectiveness of disclosure information, because small print disclosures are generally not found to cure misrepresentations in ads (Stouffer Foods 1994, CD at n. 10). Furthermore, the scope of the study's target market may dictate the importance of disclosed (and other ad) information if it is noticed (Stouffer Foods 1993b, ID at 38; see also "Concurring Statement" 1994, at n. 1). Also, for challenged ads containing both relative and absolute implied claims, researchers might consider the use of clearly separated categories for the coding of relative versus absolute open-ended responses. Finally, as was found in Stouffer Foods (1993a, CB at 16,1994, CD at 6), recent consumer behavior research may often be germane to the evaluation of multiple claims in challenged ads. This may necessitate an understanding and application of recent consumer behavior principles, such as relational processing (Meyers-Levy 1991; Stouffer Foods 1993a, CB at 16) or priming effects due to other cues found in the ads (Herr 1989; Stouffer Foods 1993a, CB at 16).

Other implications can be drawn from the control ad debate in the Stouffer case. One such implication is the importance of understanding the nature and direction of any preexisting bias that might occur in the study (Stouffer Foods 1994, CD at 17). Such an understanding can help guide the selection of an appropriate ad control type. For example, if there is a concern about a widely disseminated campaign for the challenged ad (i.e., an ad halo effect), a different ad control from a previous campaign for the brand might be considered (Kraft, Inc. 1989, IDF 126). If the issue is a pre-existing belief on which the advertiser capitalizes because of related information in the ad, a purged or tombstone control might be used, as long as the target ad did not receive extensive prior dissemination (Kraft, Inc. 1989, IDF 150).

However, a control ad group may not always be feasible. Consider, for example, a "worst case scenario" for the researcher in which (1) a different ad control can not be located, (2) the challenged ad has been disseminated widely and extensively, and (3) everything in the challenged ad (including the brand name) conveys the potentially misleading claim. Such strong halos may also negate the effectiveness of the corrected ad control option. Furthermore, certain con- trol ad groups for broadcast ads may be difficult to use in a study because of the substantial cost of modifying such an ad to delete the challenged claim in question (Maronick 1991).

Finally, researchers might be careful not to confound control ad elements or control question attributes with challenged (and other related) information in the ad (Stouffer Foods 1993b, ID at 34-35). Therefore, researchers designing studies with control questions often face a difficult choice in the selection of a control attribute on the continuum between attributes directly or indirectly associated by the consumer with the challenged claim to attributes implausibly associated with the challenged product. In summary, even when faced with these considerations and tradeoffs, the appropriate use of controls by the researcher can help to enhance the validity of extrinsic evidence presented before the Commission.

\section{Concluding Remarks}

Increasingly, methodological differences represent the majority of discussion in Commission hearings and decisions. In Stouffer Foods (1994, CD at 12), the Commission gave substantial weight to the complaint counsel's copy test, which it viewed as methodologically sound and valid. On the other hand, the lack of adherence to generally accepted principles has led the Commission either to (1) allocate less weight to such extrinsic evidence from the complaint counsel or respondent or (2) reject such evidence all together (e.g., see Stouffer Foods 1993b, ID at 35, 1994, CD at 9).

Therefore, the purpose of our review was to discuss six important copy test and ad interpretation issues found in the recent Stouffer Foods case at the FTC. These issues included: (1) relative and absolute claims, (2) interpretation of multiple ad claims, (3) control ad issues regarding application to open-ended questions, (4) control ad issues concerning pre-existing beliefs, (5) control question issues, and (6) the processing of disclosure information. An overview of generally accepted principles for copy test evidence at the FTC is provided, along with a discussion of difficult tradeoffs to consider in copy test development.

On the basis of our review, we offer three points of encouragement and caution. First, there is no such thing as a perfect copy test. As was noted in Stouffer Foods (1994, CD at 13; see also Bristol-Myers Co. 1975, CD at 744; Sudman 1995), "Perfection is not the prevailing standard for determining whether a copy test may be given any weight. The appropriate standard is whether the evidence is [reasonably] reliable and probative." Second, adherence to generally accepted principles for copy tests tends to increase the relative weight given to the evidence by the FTC. Third and finally, in the operationalization of such principles, researchers might consider carefully the trade-offs involved. This is particularly important in such decisions as the most appropriate (if any) control ad group and/or control question to employ. Such alternative consideration is likely to strengthen the preparation and provision of extrinsic evidence and copy test findings at the Commission. 


\section{References}

Alba, Joseph W. and J. Wesley Hutchinson (1987), "Dimensions of Consumer Expertise," Journal of Consumer Research, 13 (March), 411-54.

American Home Products Corp. (1981), 98 FTC 136-427.

American Home Products v. The Procter \& Gamble Co., Syntex USA, Inc., and Procter-Syntex Health Products Co. (1994), WL 727961 (D.N.J.), 1-28.

Bristol-Myers Company (1975), 85 FTC 688-754.

Campbell, Donald T. and Donald W. Fiske (1959), "Convergent and Discriminant Validation by the Multitrait-Multimethod Matrix," Psychological Bulletin, 56 (2), 81-105.

Cliffdale Associates, Inc. (1984), 103 FTC 110-202.

Cohen, Joel B. (1977), "Testimony Re: Proposed Trade Regulation Rule Concerning Advertising for Over-the-Counter Drugs," Washington, DC: Federal Trade Commission, (March 28), 3512-16.

Concurring Statement (1994), FTC Commissioner Mary L. Azcuenaga, in the Matter of Stouffer Foods Corp., FTC Docket No. 9250 (October 4), 1-6.

Cook, Thomas D. and Donald T. Campbell (1979), Quasi-Experimentation: Design and Analysis Issues for Field Settings. Boston: Houghton-Mifflin.

Darby, M. R. and E. Karni (1973), "Free Competition and the Optimum Amount of Fraud," Journal of Law and Economics, 16 (April), 67-88.

Foxman, Ellen R., Darrel D. Muehling, and Patrick A. Moore (1988), "Disclaimer Footnotes in Ads: Discrepancies Between Purpose and Performance," Journal of Public Policy \& Marketing, 7, 127-37.

FTC Enforcement Policy Statement on Food Advertising (1994), Washington, DC: Federal Trade Commission, 1-28.

FTC Guides for the Use of Environmental Marketing Claims (1992), Washington, DC: Federal Trade Commission, 1-27.

Giant Food, Inc. (1962), 61 FTC 326-63.

Gillette Co. v. Wilkinson Sword, Inc. (1991), No. 89, Civ. 3586, slip opinion at 16 (S.D.N.Y.), January 9.

Handbook of Recommended Procedures for the Trial of Protracted Cases (1960), 25 Federal Rules Decisions, 351, 425-26.

Herr, Paul (1989), "Priming Price: Prior Knowledge and Context Effects," Journal of Consumer Research, 16 (June), 67-75.

Jacoby, Jacob and George J. Szybillo (1995), "Consumer Research in FTC Versus Kraft (1991): A Case of Heads We Win, Tails You Lose?" Journal of Public Policy \& Marketing, 14 (Spring), $1-14$.

Johnson \& Johnson * Merck Pharmaceuticals Co. v. Smithkline Beecham Corp. (1992), 960 F.2d, 294-301.

Kraft, Inc. (1989), Initial Decision Findings of Fact (Sections: 1280) and Initial Decision Discussion, 114 FTC 47-115.

Kraft, Inc. (1991), Commission Decision, 114 FTC 40-46, 116-51.

Manual for Complex Litigation (1982) (Federal Practices Series), New York: Clark Boardman Company, Ltd.

Maronick, Thomas J. (1991), "Copy Tests in FTC Deception Cases: Guidelines for Researchers," Journal of Advertising Research, 31 (December), 9-17.
Mazis, Michael B., Dennis L. McNeil, and Kenneth L. Bernhardt (1983), "Day-After Recall of Listerine Corrective Commercials," Journal of Public Policy \& Marketing, 2, 29-38.

Meyers-Levy, Joan (1991), "Elaborating on Elaboration: The Distinction Between Relational and Item-specific Elaboration," Journal of Consumer Research, 18 (December), 358-367.

Mitchell, Andrew A. (1983), "Cognitive Processes Initiated by Exposure to Advertising," in Information Processing Research in Advertising, R. J. Harris, ed. Hillsdale, NJ: Lawrence Erlbaum Associates, 13-42.

Morgan, Fred W. (1990), "Judicial Standards for Survey Research: An Update and Guidelines," Journal of Marketing, 54 (1), 59-70.

Owen, Debra K. and Joyce E. Plyler (1991), "The Role of Empirical Evidence in the Federal Regulation of Advertising," Journal of Public Policy \& Marketing, 10 (1), 1-14.

Plevan, Kenneth A. and Miriam L. Siroky (1991), Advertising Compliance Handbook, 2d ed. New York: Practising Law Institute.

"Positioning Advertising Copy Testing" (1982), Journal of Advertising, 11 (4), 4-29.

Preston, Ivan L. (1987), "Extrinsic Evidence in Federal Trade Commission Deceptiveness Cases," Columbia Business Law Review, (3), 633-94.

(1989), "The Federal Trade Commission's Identification of Implications as Constituting Deceptive Advertising," Cincinnati Law Review, 57, 1243-1310.

(1992), "The Scandalous Record of Avoidable Errors in Expert Evidence Offered in FTC and Lanham Act Deceptiveness Cases," in Proceedings of the Marketing and Public Policy Conference, Paul N. Bloom and Richard G. Starr, eds. Chicago: American Marketing Association, 2-19.

Russo, J. Edward, Barbara L. Metcalf, and Debra Stephens (1981), "Identifying Misleading Advertising," Journal of Consumer Research, 8 (September), 119-31.

Shimp, Terence A. (1978), "Do Incomplete Comparisons Mislead?" Journal of Advertising Research, 18, 21-27.

Simeon Management Corp. v. FTC (1978), 579 F.2d 1137, 1146 (9th Cir.).

Standard Oil of California (1974), 84 FTC 1401.

Stewart, David W. (1995), "Deception, Materiality, and Survey Research: Some Lessons from Kraft," Journal of Public Policy \& Marketing, 14 (Spring), 15-28.

Stouffer Foods Corp. (1993a), Complaint Counsel's Brief in Support of Proposed Findings of Fact, Conclusions of Law, and Proposed Order, FTC Docket No. 9250 (May 21), 1-61.

(1993b), Initial Decision Findings of Fact (Sections: 1-196) and Initial Decision Discussion, FTC Docket No. 9250, slip opinion (August 6), 1-41.

(1993c), Post-Trial Brief of Respondent Stouffer Foods Corporation, FTC Docket No. 9250 (May 21), 1-78.

(1994), Commission Decision, FTC Docket No. 9250, slip opinion, October $4,1-21$.

Sudman, Seymour (1995), "When Experts Disagree: Comments on the Articles by Jacoby and Szybillo and Stewart," Journal of Public Policy \& Marketing, 14 (Spring), 29-34.

Thompson Medical Company, Inc. (1984), 104 FTC 648-844.

Wilkie, William L. (1985), "Affirmative Disclosure at the FTC: Objectives for the Remedy and Outcomes of Past Orders," Journal of Public Policy \& Marketing, 4, 91-111. 